\title{
How Does Opportunistic Behavior Influence Firm Size? An Evolutionary Approach to Organizational Behavior
}

August 2009

\begin{abstract}
This paper relates firm size and opportunism by showing that, given certain behavioral dispositions of humans, the size of a profit-maximizing firm can be determined by cognitive aspects underlying firminternal cultural transmission processes. We argue that what firms do better than markets - besides economizing on transaction costs - is to establish a cooperative regime among its employees that keeps in check opportunism. A model depicts the outstanding role of the entrepreneur or business leader in firminternal socialization processes and the evolution of corporate cultures. We show that high opportunismrelated costs are a reason for keeping firms' size small.
\end{abstract}

Word count: 7491

Keywords: Theory of the Firm - Transaction Cost Economics - Cultural Evolution - Opportunism Cooperation

JEL Codes: D21, D23, D01, M14, C61 


\section{Introduction}

This paper relates firm size and opportunism. We show that, given certain evolved behavioral dispositions of humans, the size of a profit-maximizing firm can be determined by cognitive aspects underlying firminternal learning processes. When taking into account social learning, the opportunism problem appears in a different light. Such processes of intra-firm cultural evolution including socialization are usually not considered a problem in the theory of the firm. We find that high opportunism-related costs are a reason for keeping firms' size small. The fruitfulness of the general idea of applying evolutionary approaches - or "Darwinian thinking" - to business, management, and organizational behavior has been the subject matter of recent debates on theories of organizations (e.g., Nicholson and White 2006, Dosi and Marengo 2007).

Transaction cost oriented concepts dominate the research agenda in the theory of the firm. These approaches postulate that a profit-maximizing firm will internalize a sequence of activities if the costs of doing so are lower than transacting the same activities through arm-length market transactions. The aim is to minimize transaction costs, hold-up, and post-contractual hazard as well as to internalize scale economies (see, as a point of origin, Coase 1937, 1992, Williamson 1975, 2002). Central to transaction cost economics explanations of the "nature of the firm" is the question of how opportunism is kept under control to facilitate gains on transaction costs - a main reason for choosing the organizational form of the firm as a particular way of coordinating individual economic activities (Arrow 1974, Williamson 1985, Holmstrom and Tirole 1989, Hill 1990, Kreps 1990, Conner and Prahalad 1996, Foss 1996, Schilling and Steensma 2002). ${ }^{1}$ The answers provided to this question emphasize measures of monitoring, governance, and the general design of incentive structures (e.g., Alchian and Demsetz 1972, Williamson 1979, Holmstrom and Milgrom 1994). This paper offers a new perspective on the role opportunistic behavior plays in determining the size of a firm. Emphasis is shifted from transaction cost arguments to processes of transmission of competing cultural variants - including opportunistic behavior - in groups of varying size by social learning, i.e., cultural evolution.

The two basic behavioral assumptions on which transaction cost analysis relies are bounded rationality and opportunism. Organizational choices and complex contracts - including employment contracts - arise in a bounded (or limited) rationality context (Williamson 1981, 1999, Nelson and Winter 1982, Cyert and March 1992, Madhok 1996, Foss 2000). Incomplete contracting results from bounded rationality and implies the impossibility to deal with complexity in all contractually relevant respects (Williamson 1981). As regards the recognition of the boundedness of rationality, this is a starting point common to both avenues, transaction cost economics and the theory of cultural evolution. Humans' constrained psychological resources are also a fundamental part of cultural transmission processes.

\footnotetext{
${ }^{1}$ Opportunistic behavior includes the hidden pursuit of private interests by the employees at the expense of the firm and implies self-interest seeking with guile.
} 
Imitating or learning from others is one of the most important means by which humans finesse the bounds of rationality (Boyd and Richerson 1993). Limits to human rationality in the face of a complex world induce individuals to adopt culturally transmitted behaviors, frequently without independent evaluation of their outcomes (Richerson and Boyd 2001). Hence, human choice between different kinds of behavior is boundedly rational: repertoires of behavior are mostly formed by imitating others. ${ }^{2}$ This can lead to adaptive but also myopic choice among the cultural variants observed. ${ }^{3}$

With respect to the second behavioral assumption, we consider, besides an inclination toward opportunistic behavior, a human disposition for cooperation. By doing so, we extend the behavioral assumptions of the transaction cost approach and provide an evolutionary explanation for behaviors of interest to organizational scholars (Nicholson 1997, Langlois 2003; Hodgson and Knudsen 2007; Field 2007). In organizations, cooperation readily emerges spontaneously in small- and medium-sized groups. Cooperation seems to be a kind of first choice for human actors (see the abundant evidence from game theory and experimental economics, e.g., Bolton and Ockenfels 2000, Güth and van Damme 1998, Fehr and Gächter 2000, Rubin 1982). This disposition is rare in nature if not uniquely human and calls for a sound explanation. For that purpose, we rely on insights from evolutionary theory on aspects of the human psychology, learning, and preferences, especially on the theory of gene-culture coevolution. Humans are unique in the degree to which they depend upon socially transmitted information (culture) to create complex adaptations (Tomasello 1996). And these evolved cultural learning capacities prepared the stage for the evolution of prosociality including cooperation: Boyd and Richerson $(1982,2002)$ and Richerson and Boyd (2005) propose that the disposition for cooperation has evolved by a process of cultural group selection that is rooted in the interaction between cultural and genetic transmission. By producing multiple behavioral equilibria between groups that comprise group-beneficial equilibria, cultural evolution endogenously generated a mechanism of equilibrium selection that can favor prosociality (Henrich 2004). ${ }^{4}$ Given multiple equilibria, cultural group selection represents a process that selects among alternative stable equilibria in favor of the ones most successful in competing with other groups. Groups with prosocial norms for cooperation had a considerable advantage over other, competing groups.

When cultural group selection became an appreciable evolutionary force, it set in motion a process of gene-culture coevolution. ${ }^{5}$ The prevalent level of cooperation based upon the prevailing social, culturally

\footnotetext{
${ }^{2}$ A cultural variant is defined as an idea, skill, belief, attitude, or value that is acquired by social learning and that determines an individual's behavior.

${ }^{3}$ Rational choice is a weak process relative to cultural transmission in the construction of behavioral repertoires (for a similar argument see Eshel et al. 1998).

4 The conformist bias, i.e., humans' evolved inclination to adopt those cultural variants that are more frequent within a group, plays an important role in maintaining intergroup cultural variation (see Boyd and Richerson 1989, Aronson et al. 2002, ch. 8; Kameda and Diasuke 2002).

${ }^{5}$ To enable this process to start, a group-beneficial variant must become common in an initial subpopulation only once. Then, the conformist effect will favor its further increase by group selection.
} 
transmitted, institutions in a group would exert selection on innate human social dispositions. Thus, these cognitive dispositions were the coevolved products of genes responding to the novel social environments created by cultural group selection. Repeated gene-culture coevolutionary cycles established social institutions in populations and caused a coevolutionary response. Over many generations this coevolutionary dynamic generated a social psychology that facilitated cooperation. This dynamic made genes as susceptible to cultural influences as vice versa. Moreover, the selective mechanisms involved in this process can favor quite different behaviors from those favored by selection on genes alone. As a result, any gene that contributed to pro-social behavior or anti-social conduct would have been undergone selection by coevolution (Richerson and Boyd 2005, p. 214; Henrich 2004).

Another link between evolved cognitive capacities - giving rise to bounded rationality - and the theory of the firm is provided by the concept of "cognitive leadership" (Witt 1998, 2007). This theory shows how a business conception motivates and coordinates firm members and how an entrepreneur can foster cooperation while holding down opportunism. Thereby, it emphasizes the crucial cognitive input of entrepreneurs and other business leaders as social role models in organizing production and trade. Central to this approach is the implementation of a business conception as a socially-shaped cognitive frame within the firm that directs the scarce resource of "human attention". If employees adopt the entrepreneurial business conception as their own cognitive frame for their firm-related activities, a firm's organization can attain a higher degree of cognitive coherence among its members, which affects the interpretation of information and the motivation to cooperatively contribute to a common goal instead of opportunistic private interests. This concept bears some resemblance to the notion of a "shared identity" within organizations (Tajfel 1982, Kogut and Zander 1996). As the size of the firm increases, the entrepreneur's or business leader's capacity to exert cognitive leadership via intense communication processes decreases. We draw on this concept to account for the outstanding role of the entrepreneur or business leader in the socialization process of employees.

In the formation of shared cognitive frames, cultural transmission based on social learning plays a crucial role. Gene-culture coevolution theory explains how the choice of a cultural trait can be based on the observable attributes of a social role model - for example, an entrepreneur or business leader - who exhibits the trait (Richerson and Boyd 2005, p. 69; Harrington Jr. 1999). In humans' evolutionary past, selection favored social learners who have been able to evaluate potential models and copy the most successful among them, thereby saving the costs of individual learning (see also Rogers 1983, Henrich and Gil-White 2001, Labov 2001). Hence, a model-based bias in cultural evolution includes a predisposition to imitate successful or prestigious individuals. In general, such an indirect bias results if social learners use the value of a second character that characterizes a model (e.g., prestige) to determine the attractiveness of that individual as a model for the primary character (e.g., a business conception and 
cooperative behavior). This method of evaluating different cultural variants is likely to be much less costly than directly evaluating these variants (Boyd and Richerson 1985, p. 135). An entrepreneur or business leader may take advantage of this human characteristic by providing a prestigious role model for social learning processes that is embedded in the business conception, for example, by demonstrating cooperative attitudes as a worth-while (e.g., Penrose 1959; Langlois 1998; Berson et al. 2008).

The paper proceeds as follows. Section 2 introduces the analytical apparatus for understanding intrafirm cultural transmission via recursion equations that account for processes of social learning that increase the frequency of some cultural variants while decreasing that of others. In addition, we derive the profit-maximizing firm size. Potential implications of the insights gained before for the relation between opportunism and firm size are the subject matter of Section 3. Section 4 concludes the paper.

\section{A model of cultural transmission processes within the firm}

To understand how corporate cultures evolve, we need to account for the processes that increase the frequency of some cultural variants and reduce that of others. ${ }^{6}$ A complex concatenation of such processes will constantly play upon any organization's culture. In this context, the agents' behavioral repertoire is crucially influenced by the process of socialization. This section illustrates how such considerations are translated into formal mathematical models. We model three basic processes, the impact of entrepreneur/leaders upon firm culture, the impact of individual learning by ordinary employees, and a firm's profit-maximizing decisions.

Within the scope of this model, we will focus on three cultural evolutionary forces that bias transmission and that are the result of gene-culture coevolutionary dynamics described above: the modelbased bias and two direct biases, the evolved inclination toward group-beneficial cultural contents favoring cooperation and a bias toward opportunistic behavior (of course, humans also have selfish interests; this trait we share with every organism). In general, cultural transmission biases are forces that arise because people's psychology makes them more likely to adopt some cultural contents rather than others, thereby changing the frequency of the different types of cultural variants in the population. ${ }^{7}$ In this context, biases can consist of an innate component and/or a cultural component acquired in an earlier episode of social learning (Richerson and Boyd 2005, p. 66). ${ }^{8}$

\footnotetext{
${ }^{6}$ The framework for this analysis is a modified and extended version of a model in XXXX.

${ }^{7}$ The forces of biased transmission acting on cultural variation are much stronger than those that shape genetic variation; they work on shorter timescales and are driven by psychological processes, not demographic events.

${ }^{8}$ Each of these biases of cultural transmission arises from the attempts of social learners to evaluate the adaptiveness of the different cultural variants they are exposed to in a setting in which information is incomplete or costly to
} 
To model the transmission of a dichotomous cultural trait we begin by labeling the variants, say $c$ and $o$, where $c$ represents the variant "cooperative behavior" and $o$ the variant "opportunistic behavior". The state of the group is determined by the frequency of employees with the variant $c$, labeled $p$. Now, the task is to find a recursion equation in discrete time that allows us to predict the frequency of $p$ in the next stage of the transmission process given its frequency in the present stage. The general model is of the form

$$
p_{t+1}=p_{t}+\text { cultural evolutionary forces (biases). }
$$

Transmission including socialization takes place from the entrepreneur or business leader to the employees and from employees to agents entering the firm in the course of firm growth. In organizations, the entrepreneur or business leader is just one source of information. Other members also influence the agenda of communication and introduce rival cognitive frames and social models (see Salancik and Pfeffer 1978, Witt 2007). We assume that an agent entering the firm is influenced by the entrepreneur and $n$ peers she is interacting with. To depict the importances of the models in different social roles in the cultural transmission process, we assign different weights, $A_{E}$ and $A_{P}$, to the models. A large value of $A_{E}$ means that the employee is disproportionately likely to acquire the cultural variant of the entrepreneur. $n A_{P}$ reflects the weight of an employee's fellow employees, whereby $A_{E}+n A_{P}=1$. The entrepreneur's influence as a role model in implementing shared cognitive frames is decreasing with a growing group size. Therefore, her weight $A_{E}$ is assumed to be dependent on the group size $n$. The total, i.e., firm size adjusted actual weight of the entrepreneur or leader is given by

$$
A_{E}=\frac{\alpha_{E}}{\alpha_{E}+n \alpha_{P}}
$$

where $\alpha_{E}$ is the basic weight (raw prestige or charisma) of the entrepreneur (see Langlois 1998) and $\alpha_{P}$ the basic weight of any given peer employee. Given this expression, the entrepreneur's influence is diluted as group size $n$ increases. Moreover, given the entrepreneur or business leader's influence, the weight of a member of the peer group is given by

acquire (Boyd and Richerson 1985). This does not imply that all biases are necessarily adaptive, especially in contemporary societies. 
(2)

$$
A_{P}=\frac{\alpha_{P}}{\alpha_{E}+n \alpha_{P}}
$$

where $\alpha_{P}$ is the basic weight of the $i$ th worker and $\alpha_{P}=\alpha_{1}=\alpha_{2}=\ldots=\alpha_{n}$. The $n$ peers' cumulative influence on the social learning process is growing with an increasing group size and a dwindling role of the entrepreneur. Moreover, the weights of the entrepreneur and the peers are normalized by the denominator so that $A_{i}$ gives the weight of the $i$ th model relative to the other models encountered by the individual in question.

To characterize the evolution of the group, we specify the probability that a particular set of role models makes an individual to acquire the cultural variant $c$. Firm employees ( $n$ in total) may be cooperative $(c)$ or opportunistic $(o)$. We assume that the entrepreneur is always cooperative. To account for the effects of new personnel joining the firm from outside, we suppose that in each time step a cohort of $n$ employees retires and is replaced by $n$ new employees who are socialized by all $n$ old employees, plus the entrepreneur. We may also interpret this process as a necessary "renewal" of the socialization of existing employees. These would then be considered as if they were personnel just joining the firm.

In addition, we assume that the $n$ new employees are initially naïve. ${ }^{9}$ New employees encounter members of their peer group at random. With these assumptions, the cultural transmission table showing the probability of agents acquiring trait $c$ or $o$ given a particular set of models (Entrepreneur/Leader, $n$ Peers) that have different total weights $\left(A_{E}, A_{P}\right)$ and group size $n$ - also determining the changing values of $A_{E}$ and $A_{P}$-yields:

\footnotetext{
${ }^{9}$ Cognitive frames, for example, emerge in a complex, unconscious, spontaneous process under the influence of information processed earlier, not least socially continent experience (Anderson 2000, ch. 3). However, we assume here that all new employees show neutral behavior when they join the firm.
} 
Table 1 The probability of agents acquiring trait $c$ or $O$ given a particular set of models (Entrepreneur/Leader, Peers) that have different total weights $\left(A_{E}, A_{P}\right)$.

\begin{tabular}{|cccc|}
\hline \multicolumn{2}{c}{ Cultural Variant of } & Probability That an Agent of the New Cohort Acquires \\
Entrepreneur/Leader & $n$ Peers & $c$ & Cultural Variant \\
\hline$c$ & $c \ldots c$ & $A_{E}+n A_{P}$ & 0 \\
$c$ & $c \ldots c, o$ & $A_{E}+(n-1) A_{P}$ & $A_{P}$ \\
$c$ & $c \ldots c, o, o$ & $A_{E}+(n-2) A_{P}$ & $2 A_{P}$ \\
$\vdots$ & $\vdots$ & $\vdots$ & $\vdots$ \\
$c$ & & & $n A_{P}$ \\
\hline
\end{tabular}

The variable $p$ measures the frequency of the $c$ type in an infinite meta population of firms of size $n$. That is, for illustrative simplicity we are here modeling only the deterministic effect of evolutionary processes. In any given firm, stochastic effects will be important. However, in an infinite population of firms with particular characteristics $p$ will perfectly describe the average frequency of the cooperative variant and $(1-p)$ the opportunistic variant. Therefore, the average pairing probability of role models in the transmission table will have $A_{E}+p n A_{P}$ probability of transmitting $c$ to each new member of a cohort and probability $(1-p) n A_{p}$ of transmitting the cultural variant $o$. So, in an infinite population of firms of size $n$, the partial recursion for the socialization phase with the frequency of $c$ after transmission, $p^{\prime}$, given that it was $p$ before transmission is expressed by

$$
p^{\prime}=A_{E}+p n A_{P}
$$

In cultural evolution, individuals are more likely to adopt some cultural variants based on their content (Boyd and Richerson 1985, p. 135; Richerson and Boyd 2005, p. 69). Such a content-based or direct bias can result from the calculation of costs and benefits associated with alternative variants or from cognitive structures that cause people to preferentially adopt some cultural variants rather than others. In general, a cultural transmission rule is characterized by direct bias if one cultural variant is more attractive than 
others. ${ }^{10}$ A directly biased transmission creates a force that increases the frequency of the culturally transmitted variant that is favored by the bias. We assume two direct learning biases here that reflect the existence of conflicting human goals: first, an employee may recognize the discrepancy between her personal effort for the firm's interests and her direct benefits accruing from it. Hence, she may lower her efforts, i.e., increasing the relative importance of her individual interests. We call this the opportunistic bias $\mu_{c o}$ favoring the cultural variant $o$ (Boyd and Richerson 1980). Second, as has been argued above, humans have an inclination toward cooperation. We label this propensity the cooperation bias $\mu_{o c}$ favoring cultural variant $c$. We suppose that each $c$ employee has a $\mu_{c o}$ chance of learning to be opportunistic and each $o$ employee a $\mu_{o c}$ chance of learning to become $c$. Hence, the partial recursion for the individual learning phase is

$$
p^{\prime \prime}=p^{\prime}-p^{\prime} \mu_{c o}+\left(1-p^{\prime}\right) \mu_{o c}
$$

where $p$ " indicates the frequency of $c$ after one complete "generation". We assume that $\mu_{c o}>\mu_{o c}$. The evolutionarily and organization theoretically interesting case is when the opportunistic cultural variant is preferred to the cooperative one. If the opposite inequality holds, then the cooperative tendencies of individuals would be sufficient to maintain group cooperation without any form of cognitive leadership. Since even the simplest human societies seem to require some form of prestige based leadership, and multi-person firms virtually always have leadership roles, this assumption makes empirical sense.

The complete recursion for $p$, obtained by substituting (3) into (4) is expressed as

$$
p^{\prime \prime}=A_{E}+p n A_{P}-\left(A_{E}+p n A_{P}\right) \mu_{c o}+\left(1-\left(A_{E}+p n A_{P}\right)\right) \mu_{o c}
$$

and models the change of $p$ in the group over one socialization and learning step. By setting the parameters of the system, we can analyze its long run behavior by conceptually iterating equation (5) recursively for many generations. For the purpose of simplification, we assume a positive value for $\mu_{c o}$ while setting $\mu_{o c}=0$ in the following. Therefore, we obtain

\footnotetext{
${ }^{10}$ As long as experimentation is not too expensive, it is plausible that directly biased transmission might evolve, as is indicated by abundant empirical evidence (e.g., Lumsden and Wilson 1981, p. 38ff; Rogers 1983, p. 217f; Labov 1994). However, when it is difficult or costly to evaluate the consequences of the cultural variants available in the population directly, then frequency-dependent or model-based bias may be more advantageous.
} 


$$
p^{\prime \prime}=A_{E}+p n A_{P}-\left(A_{E}+p n A_{P}\right) \mu_{c o} .
$$

We now calculate the equilibrium frequency of the cultural variant $c$ in the population. At equilibrium the population does not change so $p^{\prime \prime}-p=0$. We subtract $p$ from both sides of (5a). One can determine the equilibrium of the set of coupled recursions implied by (5a) by solving for $\hat{p}$ denoting the equilibrium frequency of the cooperative cultural variant $c$ :

$$
\hat{p}=\frac{1-\mu_{c o}}{1+n \mu_{c o} \frac{\alpha_{P}}{\alpha_{E}}} .
$$

The derivative of $\hat{p}$ with respect to $n, \frac{\delta \hat{p}}{\delta n}$, is negative for all $n$, i.e., given a certain charismatic potential of the entrepreneur, the level of cooperation within a firm is decreasing with firm size. Consistent with this, the derivative of $\hat{p}$ with respect to $\alpha_{E}, \frac{\delta \hat{p}}{\delta \alpha_{E}}$, is positive for all $n$, i.e., the larger an entrepreneur's charismatic potential, the higher the level of cooperation in the group for fixed $n$ and the lower the level of opportunistic behavior.

Next, we calculate the optimal firm size for a profit-maximizing firm. In this context, maximization is an analytical convenience to account for the fact that boundedly rational human agents are intendedly rational (Williamson 1981). The problem of organization is the joining of rational purposes with the cognitive limits of human actors. Therefore, optimizing behavior may be substituted by other heuristics (see Simon 1955).

We assume that each employee contributes to the firm's profit, $r_{c}$, or loss, $r_{o}\left(r_{c}, r_{o}>0\right)$. Thus, $p n r_{c}$ represents the number of cooperative employees times the profit they make. Similarly, $n(1-p)\left(-r_{o}\right)$ is the aggregate loss of a firm's income due to opportunistic employees. We represent the profit function by $R$ and, given our assumptions about the generation of profits and losses, the firm's objective becomes to find the value of $n$, i.e., the level of employment, so as to maximize profits $(n>0)$ :

$$
R=p n r_{c}+(1-p) n\left(-r_{o}\right)
$$


Substituting the equilibrium frequency of the cooperative cultural variant $c-$ denoted by equation (6) into (7) and differentiating it with respect to $n$ gives

$$
\frac{\delta R}{\delta n}=\frac{r_{c}\left(1-\mu_{c o}\right)-\mu_{c o}\left(1+\frac{\alpha_{P}}{\alpha_{E}} n\left(2+\frac{\alpha_{P}}{\alpha_{E}} \mu_{c o} n\right)\right) r_{o}}{\left(1+\frac{\alpha_{P}}{\alpha_{E}} n \mu_{c o}\right)^{2}}
$$

By setting (8) equal to zero and solving for $n$ we obtain the profit-maximizing firm size $n_{\max }$ :

$$
n_{\max }=\frac{-r_{o}+\sqrt{r_{o}\left(r_{c}+r_{o}\right)\left(1-\mu_{c o}\right)}}{\frac{\alpha_{P}}{\alpha_{E}} r_{o} \mu_{c o}},
$$

where

$$
0<\frac{\alpha_{P}}{\alpha_{E}}<1 \text { and } \mu_{c o}<\frac{r_{c}}{r_{c}+r_{o}}
$$

Treating $r_{o}$ as the only variable term and all other terms in this expression as parameters, the profitmaximizing firm size is always decreasing with an increasing $r_{o}$. Varying $\alpha_{E}$, while keeping constant all other variables in this equation, shows that the profit-maximizing firm size is growing with an increasing charismatic potential of the business leader or entrepreneur. Figure 1 shows the relationship between $n$ and $r_{o}$ for different values of $\alpha_{E}$.

\footnotetext{
${ }^{11}$ A second solution yields a negative value for $n$ and is therefore irrelevant in this context. The second derivative of $R$ with respect to $n, \frac{\delta^{2} R}{\delta n^{2}}$, is always negative. Thus, $n_{\max }$ is a maximum.
} 


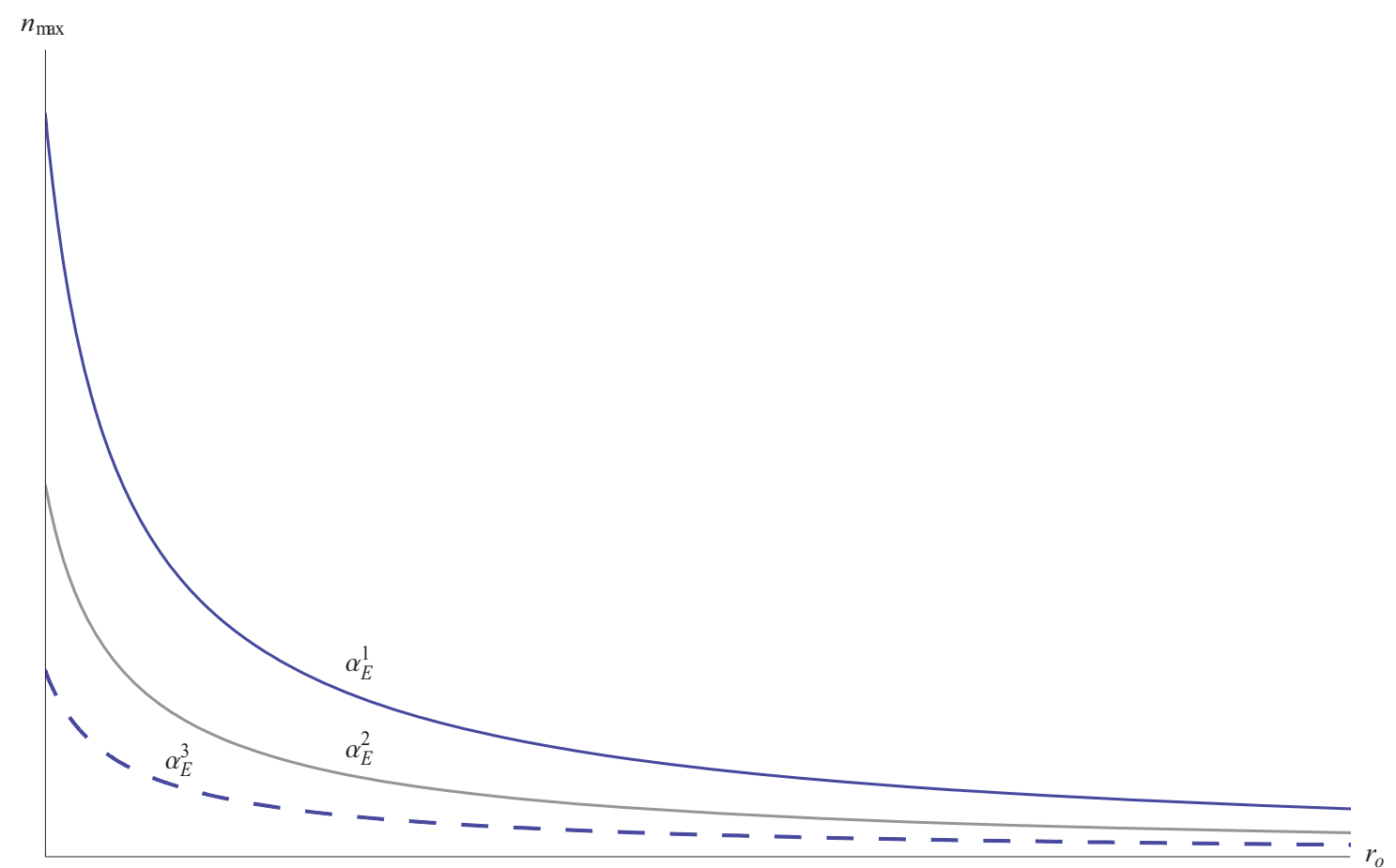

Figure 1: The relationship between profit-maximizing firm size $n_{\max }$ and the costs of opportunism $r_{o}$ for different values of $\alpha_{E}\left(\alpha_{E}^{1}>\alpha_{E}^{2}>\alpha_{E}^{3}\right)$. A profit-maximizing firm's size decreases with increasing costs of opportunism.

\section{Opportunism and firm size}

Opportunism is a central concept in the study of transaction costs. Transaction costs are significant, according to Williamson $(1971,1979)$, when there exist bounded rationality and opportunism. Moreover, the design of governance structures is a function of the perceived probability of opportunism. Therefore, minimizing transaction costs amounts to economizing on bounded rationality while simultaneously safeguarding the transactions against opportunistic behavior. A heightened probability of opportunistic behavior entails great coordination efforts, compliance costs, as well as high costs for drafting, negotiating, monitoring, safeguarding, and enforcing contingent contracts, i.e., potential opportunism causes high transaction costs (see Parkhe 1993). The organizational setting - or governance structure - of the firm is expected to economize on the writing of complex (employment) contracts and the monitoring costs that are necessary to attenuate opportunism (Alchian and Demsetz 1972). The advantages of managing opportunism internally outweigh the advantages of managing them through markets. Monitoring controls for potential costs resulting from opportunistic behavior within the firm including 
moral hazard, shirking, filtering, undisclosed subgoal pursuit, distortions, and other strategic deceits (Williamson 1999). ${ }^{12}$

The core hypothesis of transaction cost economics is that transactions are assigned to and organized within governance structures in a transaction-cost economizing manner. Coase (1937) and later Williamson (1975) argued that the size of a firm will be determined by answering the question whether it will pay to bring an extra exchange transaction under the organizing authority: "[T]the limit to the size of the firm is set where its costs of organizing a transaction become equal to the cost of carrying it out through the market" (Coase 1988, p. 7) ${ }^{13}$ Firm-internal organization restrains the opportunism that would otherwise infect market exchange and informational asymmetries are mitigated due to the fact that internal organization can be more effectively monitored (see Schilling and Steensma 2002 for a concrete example concerning licensing versus acquiring of technological know-how given the threat of opportunism; also Reinstaller 2007). Therefore, according to transaction cost economics, great costs potentially accruing from opportunistic behavior are positively correlated with firm size. ${ }^{14}$

This paper's approach, by contrast, shows that high opportunism-related costs can be an incentive for keeping firms' size small. If our model is correct, the dilution of entrepreneurs and leaders influence as organizations grow acts as a diseconomy of scale, the magnitude of which is dependent upon the leader's talent and the rate of individual learning of opportunistic strategies. We suggest the following propositions and theorems:

Proposition 1 As is shown by equation (9), for increasing potential costs of opportunistic behavior, denoted by $r_{o}$, the profit-maximizing firm size $n_{\max }$ is decreasing.

Theorem 1 Ceteris paribus, if the potential costs of opportunistic behavior are high, firm size stays small, thereby facilitating a higher level of cooperation and less opportunistic behavior within the group through intense processes of socialization.

Proposition 2 Given equation (9), the profit-maximizing firm size $n_{\max }$ is growing in $\alpha_{E}$.

\footnotetext{
${ }^{12}$ Long-term contracts - including employment contracts - executed under conditions of uncertainty cannot anticipate all future contingencies for which adaptations are required (Williamson 1979). One way to remedy this is to remove these activities from the market and organize them internally with the assistance of hierarchical incentive and control systems (Alchian and Demsetz 1972). Subgoal pursuit means that in the course of executing contracts agents also pursue private goals which may conflict with the contract's intended purpose.

${ }^{13}$ In the Coasean equilibrium of the firm, an optimizing firm chooses employment to equate marginal internal and external transaction costs per worker.

${ }^{14}$ Bounded rationality gives rise to finite spans of control and requires additional hierarchical layers (Williamson 1975, p. 126f). Therefore, the radical expansion of the firm eventually exhibits diminishing returns. These cumulative effects of control loss in growing (more and more) hierarchical organizations finally represent a limit to firm size in this model. However, this constraint takes effect in much larger firms than those considered here.
} 
Theorem 2 Ceteris paribus, the higher the entrepreneur's or business leader's charismatic potential, the greater her weight in the socialization process of employees and the greater the group size in which a cooperative regime can be maintained.

In the proposed model, an optimizing firm chooses a level of employment that enables the establishment of a cooperative regime via processes of cultural transmission and socialization to keep opportunism low. The higher the costs of opportunistic behavior are the smaller is the profit-maximizing size of the firm. The entrepreneur's or business leader's weight in the socialization process crucially influences the spreading of opportunistic behavior in a growing firm. Therefore, a monitoring regime is not the only way to counteract opportunistic behavior within the firm. In this framework, opportunism is subject to an entrepreneur's or business leader's cognitive influence via the transmission of competing cultural variants. It is not considered to be a mere behavioral constant. Moreover, the argument does not rely on a comparison of market versus firm internal interactions but focuses on intra-firm processes of cultural evolution.

Collectively shaped cognitive frames enable a high degree of cooperativeness within small, intensely communicating groups (see Witt 1998, 2000). The entrepreneur or leader can easily maintain a high level of cooperation in these smaller organizations by exerting cognitive leadership. Especially in firms consisting of highly independent, specialized employees with a great level of self-motivated responsibility-taking, opportunistic behavior would be harmful. This argument may provide an explanation for why expert firms are often small or why, for example, consultant firms have a structure that is explicitly based on small groups. Many other organizational stratagems are used to try to finesse the limitations on firm size due to the dilution effect. Franchising creates many small businesses under one umbrella. The hierarchical form of large organizations creates roles for sub-leaders in an effort to spread the burden of leadership and extend face-to-face leadership to the bottom of the organization. Therefore, a divisionalization combined with "divided entrepreneurship" (Witt 2007) is a strategy to create subgroups within which a more cooperative attitude can be maintained. Given such an internal organization, even bigger firms can reach a high level of overall intra-organizational cooperation. As a result, there would be more than one optimal - legal - firm size observed empirically.

Moreover, organizations may invest in devices to increase the charisma of the leader as in the case of American "celebrity CEOs" (the utilization of modern communication media would be one means to achieve this goal). Not least, many businesses and other organizations simply remain small. Businesses that grow too large often divest themselves of units in order to shrink. Due to the dilution effect with respect to the entrepreneur's or business leader's influence on socialization in the course of a firm's growth process, a firm - when it is trying to exceed the profit-maximizing firm size $n_{\max }$ given a certain 
$\alpha_{E}$ - may be forced to implement a monitoring regime or an intra-organizational subdivision of entrepreneurship to overcome this constraint.

Also Williamson (1981) addressed the economic purposes of the widespread adoption of divisionalization. This paper's finding that a cooperative cognitive regime is easier to employ and maintain in small groups provides a potential answer to this question that is not exclusively based on transaction cost arguments but also involves cognitive learning aspects. Moreover, across most industries and regardless of existing scale economies, firm-size distribution is skewed with only a few large enterprises and numerous small ones (Audretsch 1997). Firms in the same industry serving the same market might be expected to cluster tightly around one optimal size on the basis of most transaction cost considerations. Our model provides a ready account for the distribution of firm sizes in the same market and same industry. If the distribution of entrepreneurial and leadership talent has considerable variance, so will the equilibrium distribution of firms. This will be especially the case if even the largest firm reaches its profit maximizing size short of serving the whole market and if economies of scale are a weak determinant of profit.

The persistence of this asymmetric firm-size distribution biased toward small-scale enterprises may reflect some of the intra-organizational processes described above. Especially highly innovative firms rely on well-educated and specialized employees' initiative and cooperation - reasons to keep firms' size small to facilitate cooperation and avoid harm from opportunistic behavior. This may also prevent the founding of spin-offs by these personnel. Williamson (1975, p. 205f) has argued that an efficient procedure to introduce new products to a new market is performed by independent small firms in an industry. This may be due to the high degree of flexibility of small firms that is based upon initiative, cooperative, and creative employees. Zenger and Hesterly (1997), for instance, claimed that the observed pervasive trend toward disaggregation of US corporations into small, autonomous units is motivated by the powerful performance incentives that accompany small size. By analyzing the prerequisites for a cooperative regime within a firm, we derive another rationale for the existence of these small firms or organizations and why their organizational forms are preferred to market transactions and great hierarchical structures.

The prevailing view of why firms exist has been that they serve to keep in check the transaction costs arising from the opportunistic motivations of individuals (Williamson 2002). However, instead of reducing the latter kind of behavior, monitoring and control designed to motivate supposedly selfish actors often threatens peoples' personal sense of autonomy, decreases their intrinsic motivation, and crowds out voluntary cooperation (Ghoshal and Moran 1996, Frey and Jegen 2001). Enzle and Anderson (1993) have shown that intrinsic motivation is higher under noncontrolling and no-surveillance conditions. Cooperative employees resent tight monitoring as an implication that they are opportunistic agents (even in a cooperative regime, however, a minimum of monitoring and sanctioning is necessary due to a 
significant minority of people that plays selfish strategy). Hence, room for self-determined action is necessary to elicit a high level of initiative, cooperation, creativity, and problem solving engagement as well as intrinsic work motivation in general (also Baron and Hannan 2002). Innate dispositions toward cooperation and group loyalty increase the individual effort devoted to information updating and creativity beyond that favored by individual advantage alone. Rational, selfish thinking will tend to produce less individual learning than would be optimal from the point of view of the firm or organization due to the altruistic effects of social learning and public good problems (see Kogut and Zander 1992, Conner and Prahalad 1996).

We argue here that what firms do better than markets - besides economizing on transaction costs - is to establish a cooperative regime among its employees that "crowds in" desirable behavior, or, "positive organizational behavior" (Hodgson and Knudsen 2007; Bakker and Schaufeli 2008), based on humans' unique evolved group-regarding social predispositions. ${ }^{15}$ This "crowds out" opportunistic pursuits. At the same time, this process is a determinant of firm size; cooperation is easier to maintain in small, intensely communicating groups. Transactions that would be integrated into the governance structure of the firm according to the predictions of transaction cost economics are left to the market in the case of a cooperative regime in order to keep group size small and maintain a high level of intra-firm cooperation. This amounts to a better fit between some of humans' evolved cognitive dispositions and an organizational setting (Nicholson 1997).

\section{Conclusions}

According to Williamson (1971), the most distinctive advantage of the organizational form or governance structure of the firm is the wider variety and greater sensitivity of control instruments to attenuate opportunism and related transaction costs. In this paper, we argued that - besides transaction costs cognitive aspects of human agents are important in the organization of economic activity and the choice of the mode of organization. ${ }^{16}$ As a result of processes of gene-culture coevolution, human agents have an inclination toward cooperation, i.e., cultural learning exhibits a bias toward cooperative cultural variants. In addition, a role-model based bias takes effect in cultural transmission; both dispositions can be utilized by entrepreneurs or business leaders to influence the evolution of corporate cultures. By referring to these processes of cultural transmission and calculating the optimal size of a profit-maximizing firm, we

\footnotetext{
${ }^{15}$ The human propensity to cooperate may also be a reason why many problems of uncertainty can be attenuated by informal relational structures as alternatives to formal contract terms.

${ }^{16}$ Carter and Hodgson (2006) have shown that only few studies give unambiguous empirical support to transaction cost economics in the field of the theory of the firm. They therefore stress the importance of additional theoretical approaches (see also Gindis 2009).
} 
identified another governance structure within the organizational setting of the firm: the cooperative regime. Thus, opportunism is not the only stable behavioral equilibrium within the context of the firm (see also Hodgson 2004; Field 2007).

According to transaction cost economics, great costs potentially accruing from opportunistic behavior are positively correlated with firm size. This paper's approach, by contrast, shows that high opportunismrelated costs are a reason for a profit-maximizing firm to keep its size small. In our model, potential opportunism is a decision variable open to influence, rather than a fundamental behavioral constant.

\section{References}

Arrow, K. J. 1974. The Limits of Organization. W. W. Norton \& Company, New York.

Alchian, A. A., H. Demsetz. 1972. Production, Information Costs, and Economic Organization. American Economic Review 62(5): 777-795.

Anderson, J. R. 2000. Cognitive Psychology and Its Implications. Worth, New York.

Aronson, E., T. D. Wilson, R. M. Akert. 2002. Social Psychology. Prentice-Hall, Upper Saddle River, NJ.

Audretsch, D. B. 1997. Technological Regimes, Industrial Demography and the Evolution of Industrial Structures. Industrial and Corporate Change 6(1): 49-82.

Bakker, A. B., W. B. Schaufeli. 2008. Positive Organizational Behavior: Engaged Employees in Flourishing Organizations. Journal of Organizational Behavior 29(2): 147-154.

Baron, J. N., M. T. Hannan. 2002. Organizational Blueprints for Success in High-Tech Start-Ups. California Management Review 44(3): 8-36.

Berson, Y., S. Oreg, T. Dvir. 2008. CEO Values, Organizational Culture and Firm Outcomes. Journal of Organizational Behavior 29(5): 615-633.

Bolton, G. E., A. Ockenfels. 2000. ERC: A Theory of Equity, Reciprocity, and Competition. American Economic Review 90(1): 166-193.

Boyd, R., P. J. Richerson. 1980. Sociobiology, Culture and Economic Theory. Journal of Economic Behavior and Organization 1(2): 97-121.

Boyd, R., P. J. Richerson. 1982. Cultural Transmission and the Evolution of Cooperative Behavior. Human Ecology 10(3): 325-351.

Boyd, R., P. J. Richerson. 1985. Culture and the Evolutionary Process. University of Chicago Press, Chicago.

Boyd, R., P. J. Richerson. 1989. Social Learning as an Adaptation. Lectures on Mathematics in the Life Sciences 20: $1-20$.

Boyd, R., P. J. Richerson. 1993. Rationality, Imitation, and Tradition. R. H. Day, P. Chen, eds. Nonlinear Dynamics and Evolutionary Economics. Oxford University Press, New York, 131-149.

Boyd, R., P. J. Richerson. 2002. Group Beneficial Norms Can Spread Rapidly in a Structured Population. Journal of Theoretical Biology 215(3): 287-296.

Carter, R., G. M. Hodgson. 2006. The Impact of Empirical Tests of Transaction Cost Economics on the Debate on the Nature of the Firm. Strategic Management Journal 27(5): 461-476.

Coase, R. H. 1937. The Nature of the Firm. Economica 4(16): 386-405.

Coase, R. H. 1988. The Firm, the Market, and the Law. University of Chicago Press, Chicago.

Coase, R. H. 1992. The Institutional Structure of Production. American Economic Review 82(4): 713-719.

Conner, K. R., C. K. Prahalad. 1996. A Resource-based Theory of the Firm: Knowledge Versus Opportunism. Organization Science 7(5): 477-501.

$\mathrm{XXXX}$

Cyert, R. M., J. G. March. 1992. A Behavioral Theory of the Firm. Blackwell, Cambridge, MA.

Dosi, G., L. Marengo. 2007. On the Evolutionary and Behavioral Theories of Organizations: A Tentative Roadmap. Organization Science 18(3): 491-502.

Enzle, M. E., S. C. Anderson. 1993. Surveillant Intentions and Intrinsic Motivation. Journal of Personality and Social Psychology 64(2): 257-266. 
Eshel, I., L. Samuelson, A. Shaked. 1998. Altruists, Egoists, and Hooligans in a Local Interaction Model. American Economic Review 88(1): 157-179.

Fehr, E., S. Gächter. 2000. Cooperation and Punishment in Public Goods Experiments. American Economic Review 90(4): 980-994.

Field, A. J. 2007. Beyond Foraging: Behavioral Science and the Future of Institutional Economics. Journal of Institutional Economics 3(3): 265-291.

Foss, N. J. 1996. Knowledge-based Approaches to the Theory of the Firm: Some Critical Comments. Organization Science 7(5): 470-476.

Foss, N. J. 2000. The Theory of the Firm: An Introduction to Themes and Contributions. Foss, N. J., ed. The Theory of the Firm. Critical Perspectives on Business and Management. Routledge, London, xv-lxi.

Frey, B. S., R. Jegen. 2001. Motivation Crowding Theory: A Survey of Empirical Evidence. Journal of Economic Surveys 15(5): 589-611.

Ghoshal, S., P. Moran. 1996. Bad for Practice: A Critique of the Transaction Cost Theory. Academy of Management Review 21(1): 13-47.

Gindis, D. 2009. From Fictions and Aggregates to Real Entities in the Theory of the Firm. Journal of Institutional Economics 5(1): 25-46.

Güth, W., E. van Damme. 1998. Information, Strategic Behavior, and Fairness in Ultimatum Bargaining: An Experimental Study. Journal of Mathematical Psychology 42(2-3): 227-247.

Harrington Jr., J. E. 1999. Rigidity of Social Systems. Journal of Political Economy 107(1): 40-64.

Henrich, J. 2004. Cultural Group Selection, Coevolutionary Processes and Large-scale Cooperation. Journal of Economic Behavior and Organization 53(1): 3-35.

Henrich, J., F. J. Gil-White. 2001. The Evolution of Prestige: Freely Conferred Deference as a Mechanism for Enhancing the Benefits of Cultural Transmission. Evolution and Human Behavior 22(3): 165-196.

Hill, C. W. 1990. Cooperation, Opportunism, and the Invisible Hand: Implications for Transaction Cost Theory. Academy of Management Review 15(3): 500-513.

Hodgson, G. M. 2004. Opportunism is Not the Only Reason Why Firms Exist: Why an Explanatory Emphasis on Opportunism May Mislead Management Strategy. Industrial and Corporate Change 13(2): 401-418.

Hodgson, G. M., T. Knudsen. 2007. Firm-Specific Learning and the Nature of the Firm: Why Transaction Costs May Provide an Incomplete Explanation. Revue Economique 58(2): 331-350.

Holmstrom, B. R., P. Milgrom. 1994. The Firm as an Incentive System. American Economic Review 84(4): $972-991$.

Holmstrom, B. R., J. Tirole. 1989. The Theory of the Firm. Schmalensee, R., R. D. Willig, eds. Handbook of Industrial Organization. Volume 1, North Holland, Amsterdam, 61-133.

Kameda, T., N. Diasuke. 2002. Cost-benefit Analysis of Social/Cultural Learning in a Nonstationary Uncertain Environment: An Evolutionary Simulation and an Experiment with Human Subjects. Evolution and Human Behavior 23(5): 373-393.

Kogut, B., U. Zander. 1996. What Firms Do? Coordination, Identity, and Learning. Organization Science 7(5): 502518.

Kogut, B., U. Zander. 1992. Knowledge of the Firm, Combinative Capabilities, and the Replication of Technology. Organization Science 3(3): 383-397.

Kreps, D. M. 1990. Corporate Culture and Economic Theory. Alt, J. I., K. Shepsle, eds. Perspectives on Positive Political Economy. Cambridge University Press, Cambridge, 90-143.

Labov, W. 1994. Principles of Linguistic Change: Internal Factors. Blackwell, Oxford.

Labov, W. 2001. Principles of Linguistic Change: Social Factors. Blackwell, Oxford.

Langlois, R. N. 1998. Personal Capitalism as Charismatic Authority: The Organizational Economics of a Weberian Concept. Industrial and Corporate Change 7(1): 195-213.

Langlois, R. N. 2003. Cognitive Comparative Advantage and the Organization of Work: Lessons from Herbert Simon's Vision of the Future. Journal of Economic Psychology 24(2): 167-187.

Lumsden, C. J., E. O. Wilson. 1981. Genes, Mind, and Culture. Harvard University Press, Cambridge, MA.

Madhok, A. 1996. Crossroads - The Organization of Economic Activity: Transaction Costs, Firm Capabilities, and the Nature of Governance. Organization Science 7(5): 577-590.

Nelson, R. R., S. G. Winter. 1982. An Evolutionary Theory of Economic Change. Belknap Press of Harvard University Press, Cambridge, MA.

Nicholson, N. 1997. Evolutionary Psychology: Toward a New View of Human Nature and Organizational Society. Human Relations 50(9): 1053-1078.

Nicholson, N., R. White. 2006. Darwinism - A New Paradigm for Organizational Behavior? Journal of Organizational Behavior 27(2): 111-119. 
Parkhe, A. 1993. Strategic Alliance Structuring: A Game Theoretic and Transaction Cost Examination of Interfirm Cooperation. Academy of Management Journal 36(4): 794-829.

Penrose, E. T. 1959. The Theory of the Growth of the Firm. Basil Blackwell, London.

Reinstaller, A. 2007. The Division of Labor in the Firm: Agency, Near-Decomposability and the Babbage Principle. Journal of Institutional Economics 3(3): 293-322.

Richerson, P. J., R. Boyd. 2001. The Evolution of Subjective Commitment to Groups: A Tribal Instincts Theory. Nesse, R. M., ed. Evolution and the Capacity for Commitment. Russell Sage Foundation, New York, 186220.

Richerson, P. J., R. Boyd. 2005. Not by Genes Alone: How Culture Transformed Human Evolution. The University of Chicago Press, Chicago.

Rogers, E. M. 1983. Diffusion of Innovations. Free Press, New York.

Rubin, P. H. 1982. Evolved Ethics and Efficient Ethics. Journal of Economic Behavior and Organization 3(2-3): 161-174.

Salancik, G. R., J. Pfeffer. 1978. A Social Information Processing Approach to Job Attitudes and Task Design. Administrative Science Quarterly 23(2): 224-253.

Schilling, M. A., K. H. Steensma. 2002. Disentangling the Theories of Firm Boundaries: A Path Model and Empirical Test. Organization Science 13(4): 387-401.

Simon, H. A. 1955. A Behavioral Model of Rational Choice. Quarterly Journal of Economics 69(1): 99-118.

Tajfel, H. 1982. Social Psychology of Intergroup Relations. Annual Review of Psychology 33: 1-39.

Tomasello, M. 1996. Do Apes Ape? Heyes, C. M., B. G. Galef Jr., eds. Social Learning in Animals: The Roots of Culture. Academic Press, San Diego, 319-346.

Williamson, O. E. 1971. The Vertical Integration of Production: Market Failure Considerations. American Economic Review 61(2): 112-123.

Williamson, O. E. 1975. Markets and Hierarchies: Analysis and Antitrust Implications. Free Press, New York.

Williamson, O. E. 1979. Transaction-Cost Economics: The Governance of Contractual Relations. Journal of Law and Economics 22(2): 233-261.

Williamson, O. E. 1981. The Modern Corporation: Origins, Evolution, Attributes. Journal of Economic Literature 19(4): 1537-1568.

Williamson, O. E. 1985. The Economic Institutions of Capitalism. Free Press, New York.

Williamson, O. E. 1999. Strategy Research: Governance and Competence Perspectives. Strategic Management Journal 20(12): 1087-1108.

Williamson, O. E. 2002. The Theory of the Firm as Governance Structure: From Choice to Contract. Journal of Economic Perspectives 16(3): 171-195.

Witt, U. 1998. Imagination and Leadership - The Neglected Dimension of an Evolutionary Theory of the Firm. Journal of Economic Behavior and Organization 35(2): 161-177.

Witt, U. 2000. Changing Cognitive Frames - Changing Organizational Forms: An Entrepreneurial Theory of Organizational Development. Industrial and Corporate Change 9(4): 733-755.

Witt, U. 2007. Firms as Realizations of Entrepreneurial Visions. Journal of Management Studies 44(7): 1125-1140.

Zenger, T. R., W. S. Hesterly. 1997. The Disaggregation of Corporations: Selective Intervention, High-powered Incentives, and Molecular Units. Organization Science 8(3): 209-222. 